\section{Collection of Eggs from the Fallopian Tube of the Rat}

During the course of recent experiments in collaboration with Mr. P. C. Williams, an account of which will be published later, it has been noted that ovulation and superovulation can be produced in both intact and hypophysectomized immature rats by a single injection of mare serum gonadotrophin followed by a single injection of chorionic (urinary) gonadotrophin. In hypophysectomized rats, ovulation takes place 13-14 hours after the administration of the luteinizing hormone (chorionic gonadotrophin). The number of eggs produced may be very large; in one rat no less than forty-nine eggs were present in the Fallopian tubes.

In keeping with the observations of Long ${ }^{1}$, I have examined the Fallopian tubes of such rats in the fresh condition in order to avoid the cutting of a large number of serial sections, and to facilitate the rapid collection of the eggs. The method adopted is as follows: The Fallopian tube is uncoiled by micro. dissection. When superovulation has occurred, macroscopic observation reveals a characteristic swelling or bulging of a short length of the tube near its ovarian end. This swelling, visible to the naked eye, has a glassy appearance which is in sharp contrast to the opacity of the remainder of the tube. Under a binocular dissecting microscope the swollen part of the tube is seen to contain the eggs (Fig. 1). Each egg is surrounded by a dense mass of cumulus cells, and the cell-masses are held together by a translucent gelatinous fluid (Fig. 2). Ovulation of the normal number of eggs does not produce a cell-mass big enough to cause this swelling, though the binocular microscope enables the eggs to be seen quite easily in the tube, as described by Long. The eggs are collected by excising the egg-containing segment of the tube, and applying gentle pressure at one end of the segment to squeeze out the contents.

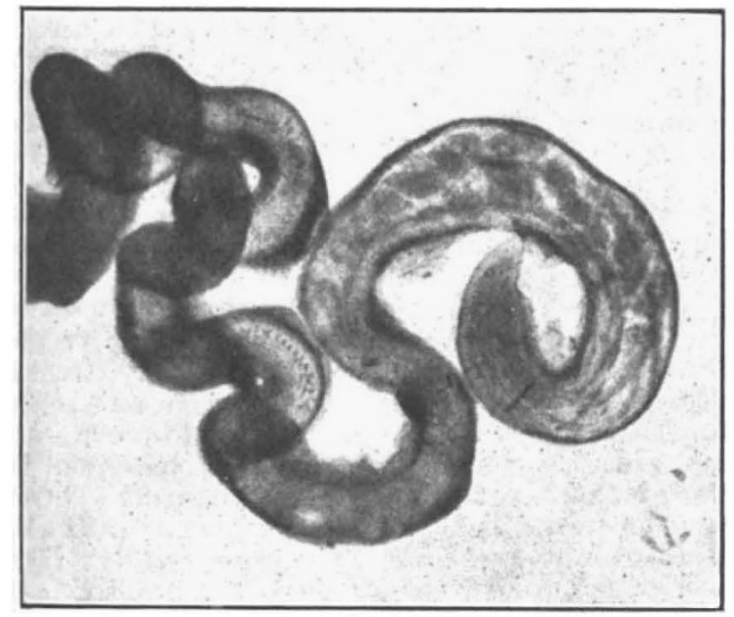

Fig. 1 .

FALLOPIAN TUBE OF HYPOPHYSECTOMIZED RAT AFTER SUPEROVULATION, SHOWING THE SWOLLEN EGG-CONTAINING SEGMENT. $(\times 15)$

Long removed the surrounding cumulus cell-mass and corona radiata by immersing the eggs in a sperm suspension, but the recovery of the eggs is then made difficult by the opacity of the fluid. I have made use of the observations of Yamane ${ }^{2}$ and Pincus and
Enzmann $^{3}$ that the dispersal of the follicular epithelial cells surrounding the egg can be effected by the supernatant fluid from a centrifuged suspension of spermatozoa previously killed by heat, or by a solution containing trypsin. The former of these methods has been applied with success. A sperm-free solution,

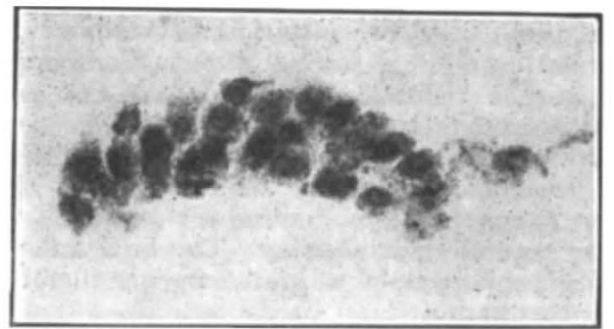

Fig. 2.

CONTENTS OF THE SWOLLEN SEGMENT, ABOUT 20 EgGS SURROUNDED BY CUMULUS CELL-MASSES CAN BE COUN'TED, $(\times 15)$

prepared in this way, causes disintegration of the cumulus and corona radiata surrounding the egg of the rat in about one hour. The eggs, now surrounded only by the zona pellucida, can then be removed with comparative ease from the medium.

I. W. Rowlands.

National Institute for Medical Research, Hampstead, N.W.3.

August 7.

${ }^{1}$ Long, J. A., Univ. Cal, Pub. Zool., 9, 105 (1912).

'Yamane, J., Cytologia, 1, 394 (1930).

${ }^{3}$ Pincus, G., and Enzmann, E. V., J. Exp. Zool., 73, 195 (1936).

\section{Vitamin $C$ in Walnuts}

THE fact that unripe walnuts (Juglans regia) contain very large amounts of vitamin C appears to have been first reported by Gergelezhiu ${ }^{1}$ in 1937. This remarkable observation that a fruit as large as the walnut contains $1,000-3,000 \mathrm{rgm}$. of vitamin $\mathrm{C}$ per $100 \mathrm{gm}$. appears to have been overlooked in English. speaking countries although the findings have since been confirmed by German workers ${ }^{2}$. It has been shown by the Russian author that the vitamin C: content is at its highest at the stage of development when the kernel is soft and just before the formation of the shell.

TABLE 1

VITAMIN C IN DIFFERENT SPECIES OF WALNUTS

\begin{tabular}{|c|c|c|c|c|c|}
\hline \multirow{3}{*}{$\begin{array}{r}\text { Juglans regia-source A } \\
\text {-source B }\end{array}$} & & \multirow{3}{*}{$\begin{array}{l}\cdots \\
\ldots\end{array}$} & \multirow[b]{2}{*}{. } & \multicolumn{2}{|c|}{ mgm. per $100 \mathrm{gm}$} \\
\hline & & & & .. & $1460-1800$ \\
\hline & & & .. & . & $1520-1640$ \\
\hline Juglans regia v. sinensis & .. & • & $\cdots$ & . & 1120 \\
\hline Juglans cathayensis & $\cdots$ & & .. & . & 860 \\
\hline Juglans nigra & .. & .. & . & . & 700 \\
\hline Juglans cordiformis & . & . & .. & .. & 680 \\
\hline Juglans rupestris ... & . & . & . & .. & 510 \\
\hline Juglans mandshurica & .. & .. & .. & .. & 410 \\
\hline
\end{tabular}

We have recently examined a number of species of walnuts. It can be seen from Table 1 that of these the cultivated edible walnut contained the highest concentration of vitamin C. The figures for the less common Juglans species must be taken as approximate since it was not possible to ensure that the specimens were analysed at the stage of development when the vitamin content was highest. 